Article

\title{
Genetic Risk Assessment of a Threatened Remnant Population of Hairy Prairie-Clover (Dalea villosa var. villosa) in the Canadian Prairie
}

\author{
Yong-Bi Fu *, Gregory W. Peterson and Ken W. Richards \\ Plant Gene Resources of Canada, Saskatoon Research Centre, Agriculture and Agri-Food Canada, \\ Saskatoon, SK S7N 0X2, Canada; E-Mails: Gregory.Peterson@agr.gc.ca (G.W.P.); \\ Ken.Richards@agr.gc.ca (K.W.R.) \\ * Author to whom correspondence should be addressed; E-Mail: Yong-Bi.Fu@agr.gc.ca; \\ Tel.: +1-306-956-7642; Fax: +1-306-956-7246.
}

Received: 4 June 2011; in revised form: 13 July 2011 / Accepted: 28 July 2011 /

Published: 8 August 2011

\begin{abstract}
Hairy prairie-clover [Dalea villosa (Nutt.) Spreng. var. villosa] is a threatened Canadian wildflower. To facilitate the efforts of conserving this threatened plant, amplified fragment length polymorphism (AFLP) technique was applied to assess genetic diversity in a remnant hairy prairie-clover population in the Canadian Prairie. Three AFLP primer pairs were employed to genotype 610 individual plants from the population and 15 plants from a North Dakota composite population, and 100 polymorphic AFLP bands were analyzed. The assayed plants displayed 23\% AFLP variation present between the remnant population and the North Dakota composite population, but maintained a high level (91\%) of AFLP variation within patches of the remnant population. The individual genetic distinctiveness measured by average AFLP dissimilarity was positively associated with latitude and negatively with elevation. The among-patch AFLP variation was significantly related to inter-patch distance, indicating local genetic differentiation within the remnant population. However, the proportions of within-patch AFLP variation were not associated with any patch characteristics assessed (i.e., patch size, perimeter, nearest neighbor distance, mean inter-patch distance). No fine-scale genetic structure was found within three large patches, suggesting little genetic correlations present for plants five meters apart. Some genetically distinctive and diverse patches were also identified. These findings indicate that the genetic risk of the remnant hairy prairie-clover population in the Canadian Prairie is low.
\end{abstract}


Keywords: Dalea villosa; endangered plant species; patch heterogeneity; genetic diversity; genetic risk; AFLP; conservation genetics

\section{Introduction}

The last decade has seen a substantial increase in the number of threatened plant species worldwide [1]. Considerable efforts have been made to protect the remnant populations of threatened plant species $[2,3]$. However, insufficient efforts have been made to assess the genetic risks of the threatened plant species [4,5]. Modern molecular techniques make a marker-based genetic diversity analysis more feasible than before to poorly known plant species [6]. The marker-based analysis can accurately measure the extent and correlative change of genetic diversity with influencing environmental and habitat factors in small plant populations and has been successfully applied to many threatened plant species $[4,7,8]$. Thus, an informative assessment on genetic risks of threatened remnant plant populations is possible.

Understanding genetic variation of plant species is important for predicting the evolutionary potential of the species and for formulating the effective strategies of conserving remnant plant populations [2,9]. Remnant populations can be theoretically predicted to have greater chance of deteriorating in genetic variation and becoming increasingly differentiated due to founder effects at the time of fragmentation, increased random genetic drift, elevated inbreeding, and reduced interpopulation gene flow [10-12]. In the long term, these small populations may have reduced ability to adapt to changing environments and potentially become extinct $[4,13,14]$. Consequently, remnant populations have gained attention in conservation and been subjected to research. However, empirical studies of small, isolated populations have yielded variable results [9,12]. Cases have been reported in which fragmented populations of some widespread plant species promoted gene flow and were not detrimental [15-17]. Several factors responsible for such discrepancy have been proposed such as interspecific longevity differential, pre-fragmentation abundance, different mating system, the presence of seed banks, and interaction of animal population and seed dispersal [12]. The influences of these factors on the extent and change of existing genetic diversity during habitat fragmentation are, however, less well understood [18,19]. Further research efforts are warranted to assess variable genetic effects of habitat loss on endangered plants [20,21].

Hairy prairie-clover [Dalea villosa (Nutt.) Spreng. var. villosa] is a member of the Fabaceae or pea family and has become a threatened Canadian wildflower (Global Rank: G5T5; COSEWIC status: threatened; Saskatchewan Provincial Rank: S1, and Provincial Protection Status: endangered). It is found in central North America, from Manitoba and Saskatchewan south to New Mexico and Texas, and from Colorado east to Michigan [22], and becomes rare in Saskatchewan, Manitoba, Montana, Iowa and Wyoming. This species is restricted to sandy sites or sand hill blowouts. Survival of the species is primarily threatened by the processes of and negatively influencing factors for sand dune stabilization [22]. As dunes continue to become vegetated via invasive weed species like leafy spurge (Euphorbia esula L.), the continuous loss of habitat for this species is expected. 
The hairy prairie-clover plant is a perennial with a woody taproot and caudex and reproduces by seeds. In the Canadian Prairie, the plants flower from late July to late August and set seed in September [23]. The total Saskatchewan population was estimated to be in the low to mid-hundreds [23]. Conservation efforts have been initiated and a recovery strategy is being developed to protect this species in the Canadian Prairie by field assessment, conservation strategy formulation, and critical habitat research [24]. However, little is known about the biology of this species and the genetic risk of small remnant patches [22].

To facilitate the efforts to conserve the remnant hairy prairie-clover populations, we conducted a genetic risk assessment of a threatened population of hairy prairie-clover in the Canadian Prairie using amplified fragment length polymorphism (AFLP) technique. The AFLP markers [25], although scored dominantly (i.e., without distinction between homozygotes and heterozygotes) and not always homologous [26], has been widely applied to assess genetic variability in many plant species and is a robust, highly effective tool for poorly known plants [27-29]. The specific objectives of this study were: (1) to assess genetic variation and spatial structure within the remnant hairy prairie-clover population and (2) to evaluate the associations of genetic variation with patch characteristics such as patch size and perimeter.

\section{Materials and Methods}

\subsection{Plant Sampling and Tissue Collection}

The remnant hairy prairie-clover population studied here was located in the Canadian Prairie and managed by the Agri-Environmental Services Branch, Agriculture and Agri-Food Canada (AAFC) (Figure 1). The population has spanned over an area of approximately 123 square kilometers. Patches of variable sizes ranging from a few to hundreds of plants are scattered over sparsely-vegetated active sand dunes or sand hill blowouts in a mosaic of forest, shrubland, grassland and barren sand patches. Some commonly associated species include its close relative D. purpurea Vent., Stipa comata Trin. \& Rupr., Calamovilfa longifolia (Hook.) Scribn., and Rosa woodsii Lindl. [23].

Two sampling strategies were applied in this study. Distribution-focus sampling selected plants from as many small patches as possible to increase the coverage of the existing plant distribution across the remnant population. This sampling yielded a collection of 188 plants from more than $70 \%$ of the previously identified patches, particularly those of sizes a few plants only. Patch-focus sampling increased sampling intensity within the selected patches of variable size to enhance the assessment of genetic variability and patchy characteristics. This sampling yielded a collection of 422 plants from 32 defined patches (i.e., those patches with clear boundary and isolation; Figure 1). In either sampling strategy, plants at least $5 \mathrm{~m}$ apart from each other were randomly selected to minimize the sampling of close genetic relatives and the GIS information for each selected plant was recorded. Young and growing leaf tissues from 2-4 cm long branch tips of selected plants were individually collected in paper envelopes and immediately stored in cool containers with dry ice. On the same day, the collected tissues were transported to and re-stored at $-80{ }^{\circ} \mathrm{C}$ at Plant Gene Resources of Canada, Saskatoon Research Centre, Agriculture and Agri-Food Canada. The collected samples were later freeze-dried and kept at $-20^{\circ} \mathrm{C}$ for AFLP analysis. 
Figure 1. Location of the remnant population of hairy prairie-clover in the Canadian Prairie and distribution of 32 defined patches with clear boundary and isolation.

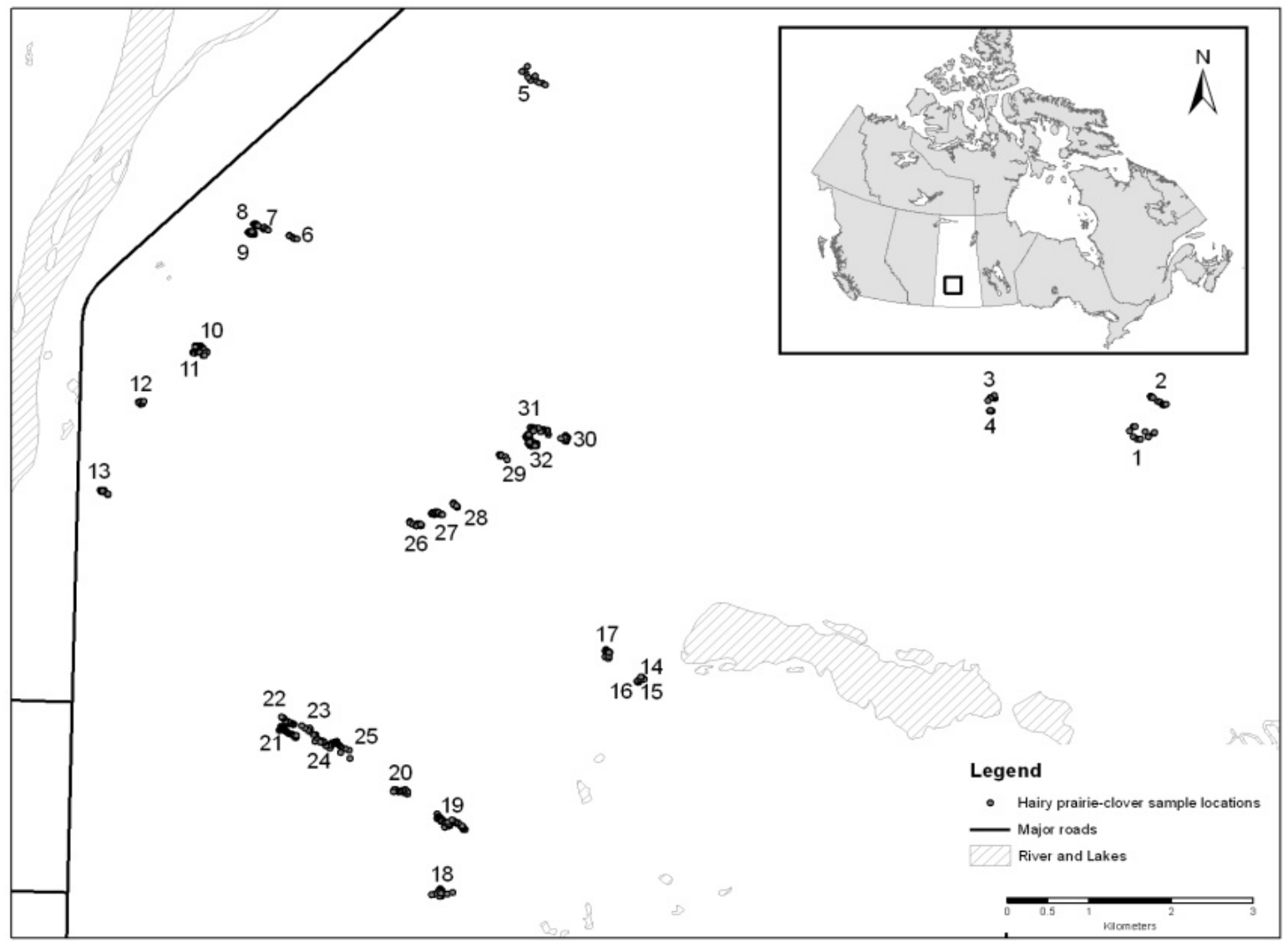

To compare the genetic diversity of this remnant population with other populations, a composite population of multiple sources representing the wide distribution of hairy prairie-clover plants in North Dakota was obtained from USDA-NRCS Plant Materials Centre, Bismarch, North Dakota. Seeds were grown in a greenhouse at the Saskatoon Research Centre and young leaf tissues were individually collected from 15 growing seedlings for this study.

\subsection{AFLP Analysis}

Genomic DNA was extracted from $50 \mathrm{mg}$ of freeze-dried leaf tissue using the E.Z.N.A. Plant DNA mini-kit (Omega Bio-Tek, Doraville, GA, USA) spin method. Extracted DNA was quantified fluormetrically with Hoechst 33258 dye (Sigma Life Sciences, Oakville, ON, Canada) against known concentration standards and diluted to $25 \mathrm{ng} \mu^{-1}$ with water. AFLP analysis was conducted according to Vos et al. [25] using restriction enzymes Eco RI and Mse I (New England Biolabs, Pickering, ON, Canada). Selective amplification was preformed with primer pairs: $\mathrm{E}+\mathrm{AGG} / \mathrm{M}+\mathrm{CTG}$, $\mathrm{E}+\mathrm{ACC} / \mathrm{M}+\mathrm{CAG}$, and $\mathrm{E}+\mathrm{ACG} / \mathrm{M}+\mathrm{CTG}$ with the Eco RI primer radiolabelled with $\gamma-{ }^{33} \mathrm{P}-\mathrm{dATP}$ (Perkin-Elmer, Waltham, MA, USA) and separated on $35 \mathrm{~cm} \times 50 \mathrm{~cm} \times 0.4 \mathrm{~mm}, 5 \%(19: 1)$ acrylamide:bisacrylamide, $7 \mathrm{M}$ urea, denaturing polyacrylamide gels. Gels were transferred to Whatman $3 \mathrm{MM}$ blotting paper, dried, and exposed against Kodak BioMax MR film for one to four days at $-80{ }^{\circ} \mathrm{C}$. Three additional randomly selected samples were duplicated across all the gels as control to minimize technique-related and scoring errors. Data from the autoradiograms were scored manually. 


\subsection{Data Analysis}

The presence/absence AFLP data for all the samples were analyzed for the level of polymorphism by counting the total number of bands and the number of polymorphic bands, calculating the proportion of polymorphic bands, and generating mean band frequencies with respect to primer and population. This was done using a SAS program written in SAS IML [30].

To assess AFLP variance components and test their statistical significance levels, analysis of molecular variance (AMOVA) was performed using Arlequin 3.0 [31] with respect to group (population or patch). This analysis allows for partitioning of the total AFLP variation into within- and among-group components, measuring inter-group distances as a proportion of the total AFLP variation residing between any two groups (Phi statistic), and estimating group-specific $F$ st [32]. Four models of genetic structuring were made: (1) remnant vs composite populations; (2) distribution-focus vs. patchfocus samples; (3) all defined patches; and (4) defined patches of size 10 or larger. The significance of variance components and inter-group distances was tested with 10,100 random permutations.

The optimal genetic structure was inferred using a model-based Bayesian method available in the BAPS software [33]. Clustering of individual plants was done using the model for non-linked markers and 20 replicate runs of the algorithm with the upper-bound values $(\mathrm{K})$ for the number of clusters ranging between 2 and 30. Recently, the BAPS analysis was found to display more advantage in inferring genetic structure over the STRUCTURE [34,35] analysis (e.g., see [36-38]). The advantage largely reflects its power of estimating optimal cluster number and admixture coefficient with much less computation time.

To assess the genetic associations of the 625 individual plants, a neighbor-joining analysis was also conducted using PAUP* [39] and a radiation tree was displayed using MEGA 3.01 [40]. The individual genetic dissimilarity was estimated using the simple matching coefficient [41] and following $\mathrm{Fu}$ [42] as the average AFLP dissimilarity of a sample against the remaining samples. A higher average dissimilarity obtained from unlinked markers means that the sample has a genetic background more distinct from the other samples [42]. This assessment was done using a SAS program written in SAS IML [30]. Linear regressions were separately performed of individual genetic distinctiveness estimates over individual position characteristics such as latitude, longitude, and elevation.

To assess the genetic associations of plants among the assayed patches, a dendrogram was generated from the inter-patch genetic distance matrix using the unweighted pair-group method, arithmetic average (UPGMA) clustering procedure in NTSYS-PC 2.01 [43]. The Mantel test was carried out to assess the correlation between patch genetic distances and patch differences in distance, elevation, and size. Simple linear regressions were separately made of within-patch AFLP variation over patch characteristics such as patch size (in term of polygon area), patch perimeter, nearest neighbour distance, and mean inter-patch distance. Some of these patch characteristics were provided by Dr. Darcy Henderson, Environment Canada.

Fine-scale spatial genetic structure within a patch was assessed using GenAlEx v6 software [44] for three defined patches of the largest sample sizes and genetic distances at individual levels were generated. Mantel test was applied to assess the association of individual genetic distances with individual position characteristics such as latitude, longitude and elevation. 


\section{Results and Discussion}

\subsection{AFLP Variation}

The three AFLP primer combinations detected a total of 131 DNA fragments among the 625 individuals, of which 128 (97.7\%) fragments were polymorphic and scored. However, only 100 polymorphic bands displayed a consistency of presence or absence in all the control samples across all the gels and thus were used for further data analysis (Table 1). The primer pair E+ACC/M+CAG had the highest number of polymorphic bands (35), while the primer pair E+AGG/M+CTG had the highest mean band frequency of 0.471 . The frequencies of all the polymorphic bands ranged from 0.002 to 0.998 and averaged 0.401. A substantial proportion of the polymorphic bands (i.e., 45\%) had frequencies smaller than 0.01 . These frequency distributions suggest that the assayed primer combinations sampled various parts of hairy prairie-clover genomes. The finding of the high level (97.7\%) of AFLP polymorphism indicates that this species is genetically highly heterogeneous and is consistent with the observation of the outcrossing nature of this species by bee-pollination, although the extent of outcrossing remains unknown. Two closely related species D. purpurea Vent. and D. candida Michx. ex Willd. are both highly outcrossing, being pollinated by a diversity of bee and fly species [45]. Such a high level of AFLP polymorphism is expected for an outcrossing plant species [46] and is compatible with those AFLP findings reported in other outcrossing plant species native to North America [27-29,47,48].

Table 1. Patterns of amplified fragment length polymorphism (AFLP) in the remnant population of hairy prairie-clover with respect to AFLP primer pair.

\begin{tabular}{|c|c|c|c|c|}
\hline \multirow{2}{*}{ Primer Pair } & \multirow{2}{*}{$\begin{array}{c}\text { Percentage of } \\
\text { polymorphic bands } \\
\text { observed }\end{array}$} & \multirow{2}{*}{$\begin{array}{c}\text { Number of } \\
\text { polymorphic } \\
\text { bands used }\end{array}$} & \multicolumn{2}{|c|}{ Frequency of polymorphic bands } \\
\hline & & & Mean & Range \\
\hline $\mathrm{E}+\mathrm{AGG} / \mathrm{M}+\mathrm{CTG}$ & 100 & 33 & 0.471 & $0.002-0.998$ \\
\hline $\mathrm{E}+\mathrm{ACC} / \mathrm{M}+\mathrm{CAG}$ & 95.7 & 35 & 0.410 & $0.002-0.998$ \\
\hline $\mathrm{E}+\mathrm{ACG} / \mathrm{M}+\mathrm{CTG}$ & 97.3 & 32 & 0.319 & $0.002-0.997$ \\
\hline All primers & 97.7 & 100 & 0.401 & $0.002-0.998$ \\
\hline
\end{tabular}

\subsection{Population Variation}

Analysis of AFLP variation revealed 23.3\% AFLP variation present between the remnant population in Saskatchewan and the composite population from North Dakota (Table 2). The population-specific proportional variation $(F \mathrm{st})$ was 0.2331 in the remnant population and 0.2306 in the composite population. These population-specific $F$ st values measure the extent to which each population differs genetically from the combined population as a whole [49], thus suggesting a little more distinctness for the Saskatchewan threatened population than for the North Dakota composite population in the centre distribution of the species. Such AFLP finding is somehow expected, as the plants from the composite population may represent various seed sources in North Dakota. Within the remnant population, the plants collected from distribution-focus and patch-focus sampling displayed non-significant differentiation in AFLP variation (Table 2). This suggests that the two sampling 
strategies yielded little difference in sampling AFLP variation. The patterns of patch AFLP variation presented and discussed in the later section should be representative for the whole remnant population.

Table 2. The results for the analysis of molecular variance of 625 assayed plants of hairy prairie-clover with four models of genetic structuring.

\begin{tabular}{llll}
\hline Model and source of variation & $\boldsymbol{d} \boldsymbol{f}$ & Variance components & \% variation \\
\hline Remnant $v$ s composite populations & & & \\
Between populations & 1 & 2.07 & $23.30^{* * * *}$ \\
Within populations & 623 & 6.82 & 76.70 \\
\hline Distribution- $v$ s patch-focus samples & & & \\
Between groups & 1 & 0.01 & $0.05 \mathrm{~ns}$ \\
Within groups & 608 & 6.79 & 99.95 \\
\hline All defined patches & & & \\
Among patches & 31 & 0.64 & $9.52^{* * * *}$ \\
Within patches & 390 & 6.08 & 90.48 \\
\hline Defined patches (of size $>9$ ) & & & $8.49 * * * *$ \\
Among patches & 22 & 0.57 & 91.51 \\
Within patches & 345 & 6.11 & $P<0.0001$. \\
\hline
\end{tabular}

Note: $\mathrm{ns}$ is for non-significance at $P>0.05 ; * * * *$ for statistical significance at $P<0.0001$.

The model-based Bayesian inference of the genetic structure among the 625 plants sampled from the remnant and composite populations revealed five optimal clusters with the highest log likelihood of $-13,578.6$ (Figure $2 \mathrm{~A})$. Only three plants $(0.5 \%)$ had multiple memberships of various clusters. The cluster size ranged from 18 for cluster 5 to 221 for cluster 3 . The smallest, cluster 5 , consisted of 15 individuals from the North Dakota composite population and three plants from the remnant population and was the most divergent cluster (Figure 2B). The membership composition of other four clusters was not unique with respect to plant location and patch. Overall, the genetic structure presented in the four optimal clusters for the remnant Saskatchewan population was weak (Figure 2B).

The assessment of individual genetic association from both remnant and composite populations revealed not only the heterogeneous nature of this species, but also little distinctness of the hairy prairie-clover plants in the North Dakota composite population from the remnant Saskatchewan population (Figure 3). The assayed plants were loosely clustered into five clusters, similar to the model-based structure inference (Figure 2). These clusters did not seem to be associated with the plant locations, nor with the defined patches. More interestingly, the plants from the North Dakota composite population did not form their own cluster, differing slightly from the BAPS inference (Figure 2A), but seemed to be derived from a subgroup of the Saskatchewan plants. It is possible that the composite plants assayed may not truly reflect the original source populations, as the 15 sampled seeds may be offspring of the original composite population with some level of genetic change. Also, as expected, there was no clear separation among the plants either from patch-focused or distribution-focus sampling. 
Figure 2. Genetic structure of 625 assayed hairy prairie-clover plants inferred using the BAPS software. (A) five optimal clusters; (B) genetic divergence among five optimal clusters.
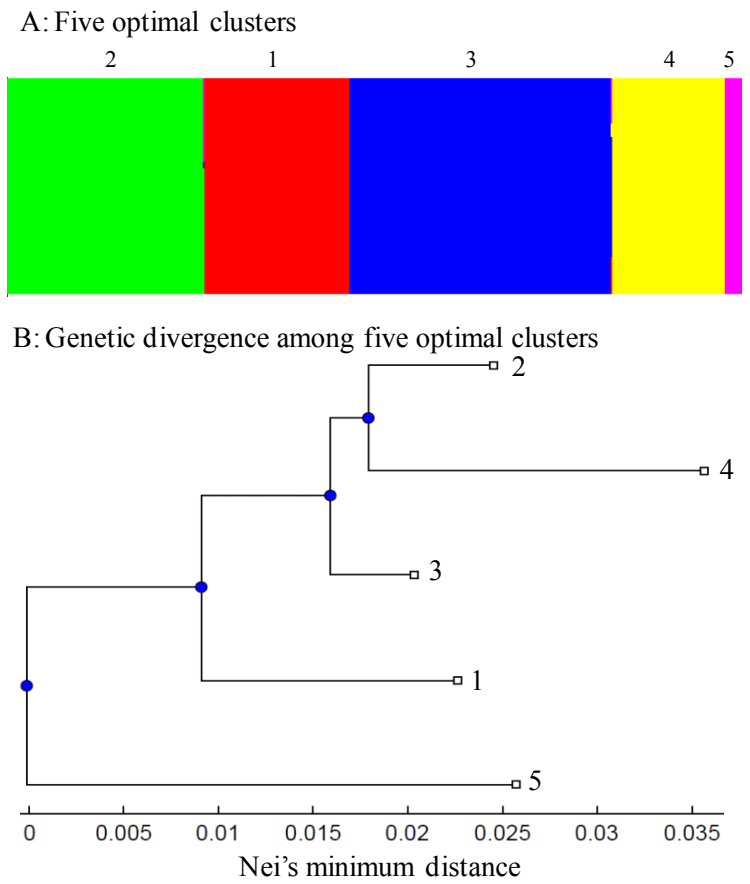

Figure 3. AFLP-based neighbor-joining dendrogram of 625 assayed plants of hairy prairie-clover. The plants of defined patches are labeled with patch number, from the distribution-focus sampling with letter $\mathrm{n}$, and of the North Dakota composite population with s and highlight.

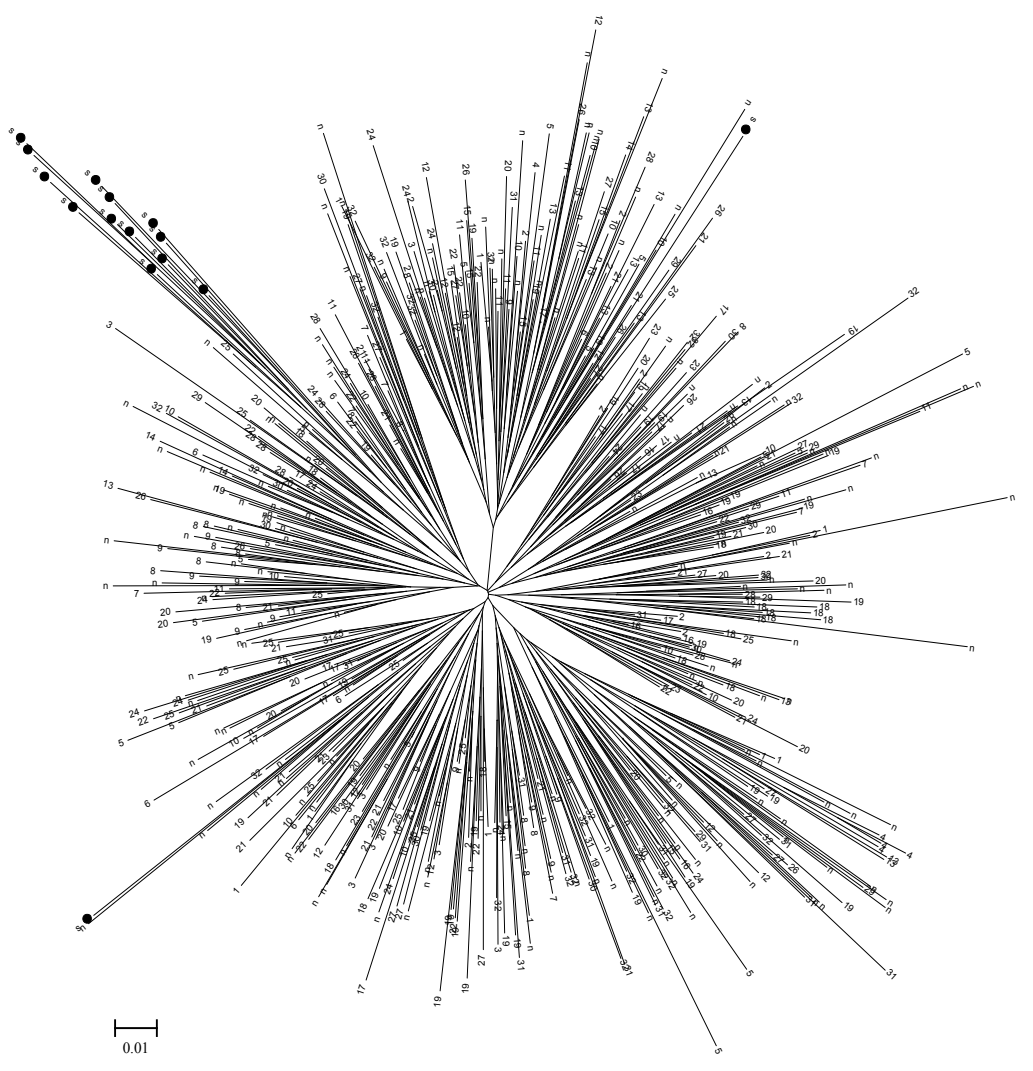


The assessment of individual genetic distinctiveness with plant location characteristics revealed that the plants in this remnant population were significantly associated with latitude and elevation readings, but not with longitude reading (Figure 4). These associations, although explaining relatively small proportion of variation, might signal that more gene flow had occurred in the south than the north sides of the population, and similarly, more gene flow for the plants on the hills than on the bottom of sand dunes. These patterns of variation could be generated due to restricted seed dispersal, limited bee pollination, or directed sand movement.

Figure 4. Correlation analysis among the genetic distinctiveness estimates of individual hairy prairie-clover plants, site latitude $(\mathbf{A})$ and elevation $(\mathbf{B})$.

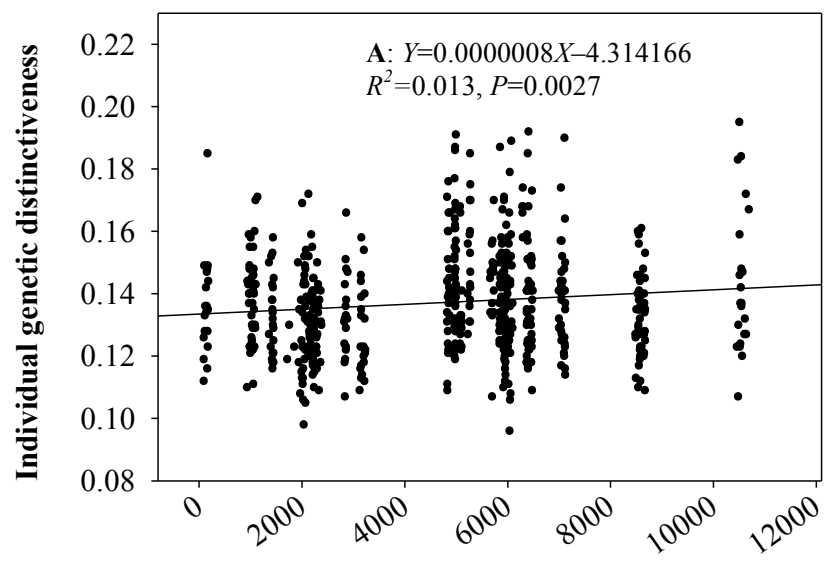

Latitude (UTM 57226600+)

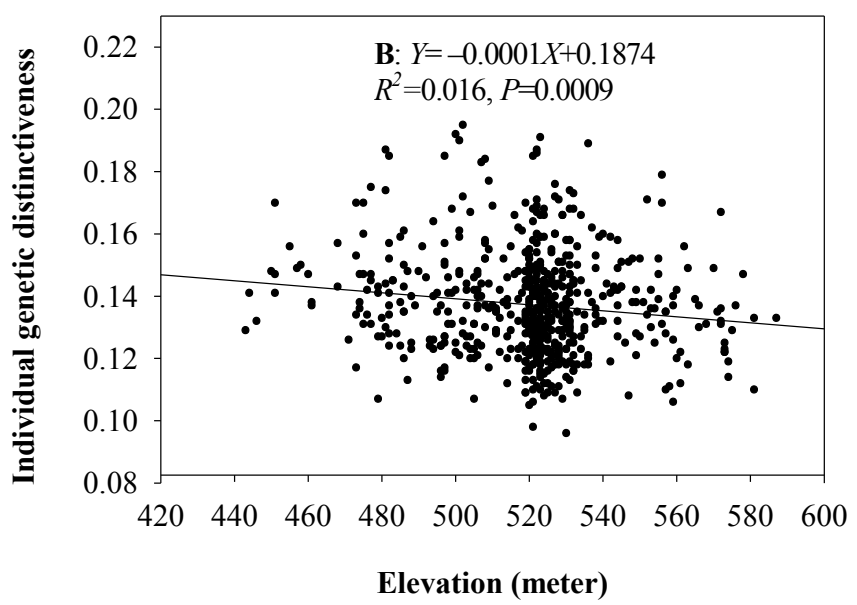

\subsection{Patch Variation}

An analysis of AFLP variation among the 32 defined patches was made. These patches had sample sizes ranging from 3 to 40 and averaging 13.2 (Figure 5). Nine patches had a sample size smaller than 10 and three patches had a sample size larger than 20. The AFLP analysis showed that $90.5 \%$ of the total AFLP variation resided within defined patches and only 9.5\% existed among various defined patches (Table 2). Removing patches of size less than 10 generated similar results with $91.5 \%$ of the total AFLP variation residing within the patches (Table 2). Thus, a patch of considerable size in this population maintained a relatively high level of genetic diversity. This may also help to explain the 
weak genetic structure observed at the individual plant level (Figure 3), as some plants shared more genetic backgrounds with plants from different patches than those within patches.

Estimates of patch-specific proportional AFLP variation $(F \mathrm{st})$ ranged from 0.086 to 0.118 and averaged 0.098 (Figure 5). The assessment of these patch-specific $F$ st values with patch characteristics revealed non-significant associations of patch genetic variation with patch size (in term of polygon area), patch perimeter, nearest neighbour distance, and mean inter-patch distance (results not shown). These patterns of non-significant association remain the same when only 23 patches of size greater than 9 were considered. These findings indicate that these patch characteristics may not directly contribute to the change in within-patch AFLP variation if any. A patch of several plants should maintain considerable genetic variation [48].

Figure 5. AFLP-based UPGMA dendrogram of the assayed plants in the 32 defined patches within the remnant population of hairy prairie-clover, along with patch sample size $(\mathrm{P} s)$ and patch-specific proportional AFLP variation $(F \mathrm{st})$. A patch is labelled with a letter $\mathrm{P}$ followed by a number.

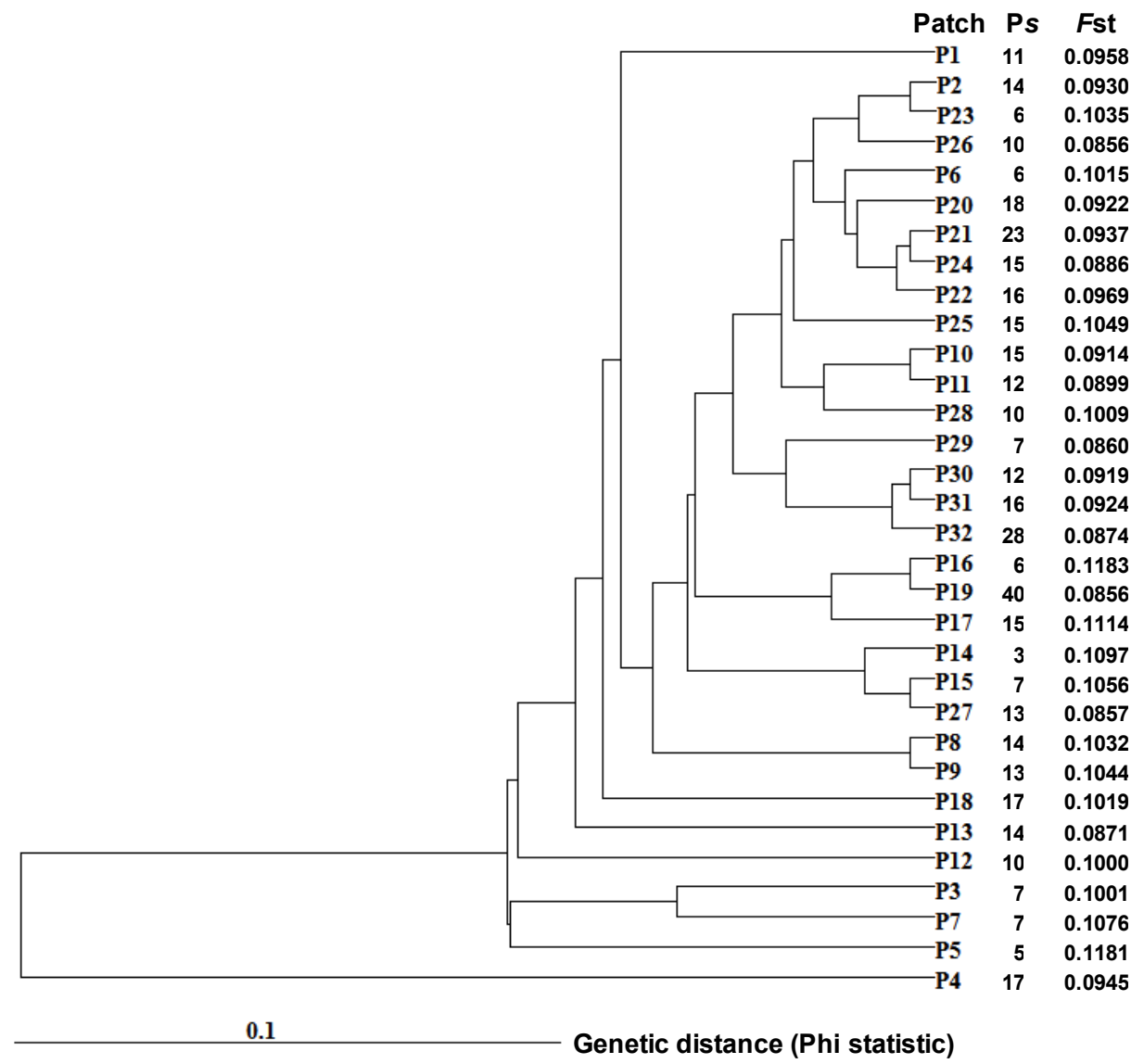

The correlation analysis of patch genetic distances with patch differences in distance, elevation, and size revealed a significant association with geographic distances (Figure 6), not with patch elevation and size. A patch of plants were more genetically distinctive to a patch far away than to a patch nearby. The assessment of patch genetic associations showed the most genetically distinctive patch was patch $\# 4$, followed by patch $\# 5, \# 7, \# 3$, and \#12 (Figure 5). Identification of these genetically distinctive patches is useful for the effective in situ management of the remnant population and for sampling 
germplasm for ex situ conservation.

Figure 6. Correlation analysis between genetic and geographic distances for the 32 defined patches within the remnant population of hairy prairie-clover.

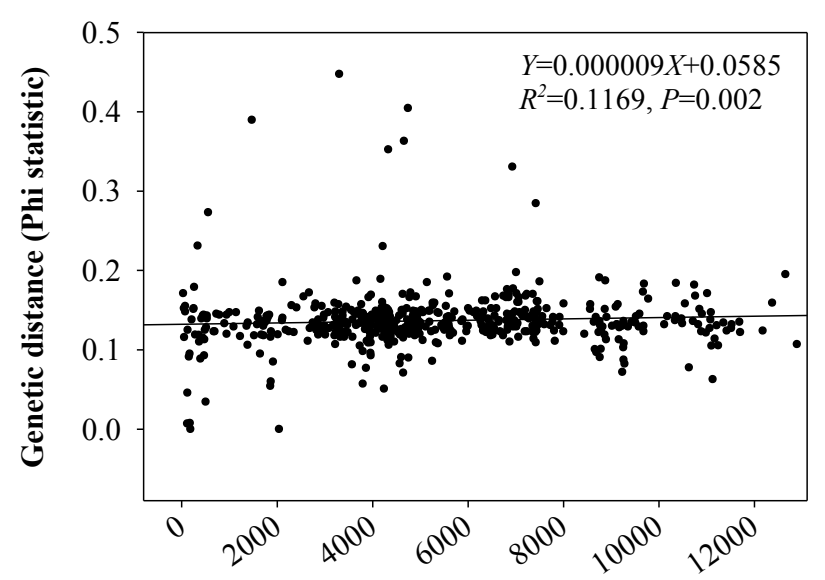

Geographic distance (meter)

\subsection{Spatial Variation within Patches}

Fine-scale spatial genetic variation was examined within three large patches (i.e., patch\#19, \#21, \#32 with sample sizes 40, 23, 28, respectively). The physical areas for these three patches ranged from 50 to $100 \mathrm{~m}$ long and 20 to $40 \mathrm{~m}$ wide and were estimated in the polygon areas of 8668,3955 , and $6821 \mathrm{~m}^{2}$, respectively. However, no spatial genetic structure was found in any patches, as none of the estimated autocorrelation coefficients were statistically significant at $P<0.05$ (results not shown). This was further confirmed by the Mantel test finding non-significant individual genetic associations with individual sampled locations within the patches (results not shown). These findings indicate the presence of little genetic correlation among plants five meters apart within each assayed patch. The lack of fine-scale genetic structure may reflect the sampling bias of excluding plants within five meters. It is possible that some fine-scale genetic structure exists within five meter distance due to limited seed dispersal [50]. Also, relatively dense plants (i.e., roughly 2-4 plants $/ \mathrm{m}^{2}$ ) growing nearly continuously within each patch may signal some genetic relatedness present among nearby plants.

\subsection{Implications for Hairy Prairie-Clover Conservation}

The patterns of AFLP variation presented here are useful to the management and conservation of hairy prairie-clover in the Canadian Prairie. First, the assayed patches appear to be maintaining large genetic diversity, implying that the genetic impact of random drift and inbreeding was small (if any) in these patches. This implication was also supported by another two findings that the patch AFLP variation was not significantly associated with patch size and the hairy prairie-clover plants from patch-focus and distribution-focus sampling displayed little AFLP differentiation across the remnant population.

Second, the findings of large AFLP variation and non-significant spatial variation with a patch also imply little genetic risk for this remnant population. The conservation effort may be emphasized less 
on genetic factors and more on reproductive biology and ecological attributes of the population. The maintenance of active bee pollinations including suitable habitat for nesting appears to be crucial to avoid possible genetic risks. Further studies on plant regeneration ability associated with various ecological and environment factors may yield useful information for long-term conservation of this population.

Third, the significant association of patch variation with inter-patch distance implies that the genetic management may be focused on patches that are far apart, particularly those patches in the north side of the remnant population. More attention should be paid to the most genetically distinctive patches such as patch $\# 4, \# 5, \# 7, \# 3$, and $\# 12$. Gene flow may be relatively limited for plants in the north side of the population and located on the bottom of sand dunes.

Fourth, the revealed patterns of genetic variation within the population are useful for sampling hairy prairie-clover plants for patch restoration. The estimated genetic distinctiveness and genetic distinctive patches should provide some guide on the effective sampling of genetic diversity either for restoration or ex situ conservation. The patches in the south side of the population tended to have more AFLP variation and the plants in the bottom of sand dunes may not necessarily have more AFLP variation. Also, seeds from a few patches should capture considerable genetic variation harbored in this population.

Fifth, it remains unknown how general these patterns of AFLP variation are with respect to other hairy prairie-clover populations in the Canadian Prairie or other sand dune specialist species. Given the finding of large AFLP variation and the nature of outcrossing, however, it is not difficult to reason that the genetic risk may be relatively low for the other remnant populations in the Canadian Prairie [48]. Further genetic and ecologic studies with more populations in the northern range of the species distribution should yield more useful information to identify the potential risks of the remnant populations.

\section{Conclusions}

This diversity analysis revealed large AFLP variation and non-significant spatial variation with patches of hairy prairie-clover, suggesting low genetic risk for this remnant hairy prairie-clover population. The revealed patterns of AFLP variation were informative to the management and conservation of hairy prairie-clover in the Canadian Prairie.

\section{Acknowledgements}

This research was part of an interdepartmental recovery effort for the threatened hairy prairie-clover led by Darcy Henderson, Environment Canada, and partially funded by the Interdepartmental Recovery Fund of Canada. The authors would like to thank Darcy Henderson for his leadership in the effort, advice in the sampling, and assistance in the description of patch distribution (Figure 1) and characteristics; Bill Houston for his support for the research; Sarah Lowe and Hüseyin Uysal for their technical assistance in field sampling and AFLP genotyping; Wayne L. Duckwitz for providing the seeds of the North Dakota composite population; and three anonymous reviewers for their helpful comments on an early version of this manuscript. 


\section{References}

1. The IUCN Red List of Threatened Species. International Union for Conservation of Nature and Natural Resources, Cambridge, UK, 2011. Available online: http://www.iucnredlist.org/ (assessed on 2 August 2011).

2. Falk, D.A.; Holsinger, K.E. Genetics and Conservation of Rare Plants; Oxford University Press: Oxford, UK, 1991.

3. Carroll, S.P.; Fox, C.W. Conservation Biology: Evolution in Action; Oxford University Press: Oxford, UK, 2008.

4. Kramer, A.; Havens, K. Plant conservation genetics in a changing world. Trends Plant Sci. 2009, 14, 599-607.

5. Miller, T.K.; Allen, C.R.; Landis, W.G.; Merchant, J.W. Risk assessment: Simultaneously prioritizing the control of invasive plant species and the conservation of rare plant species. Biol. Conserv. 2010, 143, 2070-2079.

6. DeSalle, R.; Amato, G. The expansion of conservation genetics. Nat. Rev. Genet. 2004, 5, 702-712.

7. Schaal, B.; Leverich, W. Population genetic issues in ex situ plant conservation. In Ex Situ Plant Conservation: Supporting Species Survival in the Wild; Guerrant, E.O., Havens, K., Maunder, M., Eds.; Island Press: Washington, DC, USA, 2004; pp. 267-285.

8. Honnay, O.; Adriaens, D.; Coart, E.; Jacquemyn, H.; Roldan-Ruiz, I. Genetic diversity within and between remnant populations of the endangered calcareous grassland plant Globularia bisnagarica L. Conserv. Genet. 2007, 8, 293-303.

9. Groom, M.J.; Meffe, G.K.; Carroll, C.R. Principles of Conservation Biology, 3rd ed.; Sinauer Associates: Sunderland, MA, USA, 2006.

10. Templeton, A.R.; Shaw, K.; Routman, E.; Davis, S.K. The genetic consequences of habitat fragmentation. Ann. Mo. Bot. Gard. 77, 13-27.

11. Ellstrand, N.; Elam, D. Population genetic consequences of small population size: Implications for plant conservation. Annu. Rev. Ecol. Syst. 1993, 24, 217-242.

12. Young, A.; Boyle, T.; Brown, T. The population genetic consequences of habitat fragmentation for plants. Trends Ecol. Evol. 1996, 11, 413-418.

13. Godt, M.J.W.; Hamrick, J.L. Allozyme diversity in the endangered pitcher plant Sarracenia rubra ssp. alabamensis (Sarraceniaceae) and its close relative S. rubra ssp. rubra. Am. J. Bot. 1998, 85, 802-810.

14. Thomas, C.D.; Cameron, A.; Green, R.E. Extinction risk from climate change. Nature 2004, 427, 145-148.

15. Honnay, O.; Coart, E.; Butaye, J.; Adriaens, D.; Roldan-Ruiz, I. Low effects of present and historical landscape configuration on population genetic structure of Anthyllis vulneraria. Biol. Conserv. 2006, 127, 411-419.

16. Culley, T.M.; Sbita, S.J.; Wick A. Population genetic effects of urban habitat fragmentation in the perennial herb Viola pubescens (Violaceae) using ISSR markers. Ann. Bot. 2007, 100, 91-100.

17. Geert, A.V.; Rossum, F.V.; Triest, L. Genetic diversity in adult and seedling populations of Primula vulgaris in a fragmented agricultural landscape. Conserv. Genet. 2007, 9, 845-853. 
18. Schmidt, K.; Jensen, K. Genetic structure and AFLP variation of remnant populations in the rare plant Pedicularis palustris (Scrophulariaceae) and its relation to population size and reproductive components. Am. J. Bot. 2000, 87, 678-689.

19. Vandepitte, K.; Jacquemyn, H.; Roldan-Ruiz, I.; Honnay, O. Landscape genetics of the self-compatible forest herb Geum urbanum: Effects of habitat age, fragmentation and local environment. Mol. Ecol. 2007, 16, 4171-4179.

20. Young, A.G.; Brown, A.H.D.; Zich, F.A. Genetic structure of fragmented populations of the endangered Daisy Rutidosis leptorrhynchoides. Conserv. Biol. 1999, 13, 256-265.

21. Edwards, A.L.; Wiltshire, B.; Nickrent, D.L. Genetic diversity in Astrangalus tennesseensis and the federal endangered Dalea foliosa (Fabaceae). J. Torrey Bot. Soc. 2004, 131, 279-291.

22. Smith, B. COSEWIC Assessment and Status Report on the Hairy Prairie-Clover Dalea villosa var. villosa in Canada; Committee on the Status of Endangered Wildlife in Canada: Ottawa, Canada, 1998; pp. 1-22.

23. Godwin, B.; Thorpe, J. Limited Report: Targeted Surveys for Plant Species at Risk in Elbow, Dundurn, and Rudy-Rosedale AAFC-PFRA Pastures, 2006; SRC Pub No. 11997-1E07; Saskatchewan Research Council: Saskatoon, SK, Canada, 2007.

24. Henderson, D. Canadian Wildlife Service, Environment Canada, Saskatoon, Canada. Personal Communication, 2010.

25. Vos, P.; Hogers, R.; Bleeker, M.; Reijans, M.; van De Lee, T.; Hornes, M.; Frijters, A.; Peleman, J.; Kuiper, M.; Zabeau, M. AFLP: A new technique for DNA fingerprinting. Nucleic Acids Res. 1995, 23, 4407-4414.

26. Koopman, W.J.M. Phylogenetic signal in AFLP data sets. Syst. Biol. 2005, 54, 197-217.

27. Larson, S.R.; Waldron, B.L.; Monsen, S.B. AFLP variation in agamospermous and dioecious bluegrasses of western North America. Crop Sci. 2001, 41, 1300-1305.

28. Fu, Y.B.; Thompson, D.; Willms, W.; Mackay, M. Long-term grazing effects on genetic variability in mountain rough fescue. Rangel. Ecol. Manag. 2005, 58, 637-642.

29. Qiu, J.; Fu, Y.B.; Bai, Y.; Wilmshurst, J.F. Patterns of amplified restriction fragment polymorphism in natural populations and corresponding seed collections of plains rough fescue (Festuca hallii). Can. J. Bot. 2007, 85, 484-492.

30. The SAS System for Windows V8.02; SAS Institute Incorporated: Cary, NC, USA, 2004.

31. Excoffier, L.; Laval, G.; Schneider, S. Arlequin ver. 3.0: An integrated software package for population genetics data analysis. Evol. Bioinf. Online 2005, 1, 47-50.

32. Excoffier, L.; Smouse, P.E.; Quattro, J.M. Analysis of molecular variance inferred from metric distances among DNA haplotypes: Application to human mitochondrial DNA restriction data. Genetics 1992, 131, 479-491.

33. Corander, J.; Marttinen, P.; Sirén, J.; Tang, J. Enhanced Bayesian modelling in BAPS software for learning genetic structures of populations. BMC Bioinf. 2008, 9, 539.

34. Pritchard, J.; Stephens, M.; Donnelly, P. Inference of population structure using multilocus genotype data. Genetics 2000, 155, 945-959.

35. Falush, D.; Stephens, M.; Pritchard, J.K. Inference of population structure using multilocus genotype data: dominant markers and null alleles. Mol. Ecol. Notes 2007, 7, 574-578. 
36. Latch, E.K.; Dharmarajan, G.; Glaubitz, J.C.; Rhodes, O.E. Relative performance of Bayesian clustering software for inferring population substructure and individual assignment at low levels of population differentiation. Conserv. Genet. 2006, 7, 295-302.

37. Smýkal, P.; Kenicer, G.; Flavell, A.J.; Corander, J.; Kosterin, O.; Redden, R.J.; Ford, R.; Coyne, C.J.; Maxted, N.; Ambrose, M.J.; et al. Phylogeny, phylogeography and genetic diversity of the Pisum genus. Plant Genet. Resour. 2010, 9, 4-18.

38. Kalinowski, S.T. The computer program structure does not reliably identify the main genetic clusters within species: Simulations and implications for human population structure. Heredity 2011, 106, 625-632.

39. Swofford, D.L. PAUP*. Phylogenetic Analysis Using Parsimony (*and Other Methods), Version 4; Sinauer Associates: Sunderland, MA, USA, 1998.

40. Kumar, S.; Tamura, K.; Nei, M. MEGA3: Integrated software for molecular evolutionary genetics analysis and sequence alignment. Briefings Bioinf. 2004, 5, 150-163.

41. Sokal, R.R.; Michener, C.D. A statistical method for evaluating systematic relationships. Univ. Kansas Sci. Bull. 1958, 38, 1409-1438.

42. Fu, Y.B. Genetics redundancy and distinctness of flax germplasm as revealed by RAPD dissimilarity. Plant Genet. Resour. 2006, 4, 177-124.

43. Rohlf, F.J. NTSYS-pc 2.1: Numerical Taxonomy and Multivariate Analysis System; Exeter Software: New York, NY, USA, 1997.

44. Peakall, R.; Smouse, P.E. GenAlEx 6: Genetic Analysis in Excel. Population Genetic Software for Teaching and Research; The Australian National University: Canberra, Australia, 2005.

45. Richards, K.W. Plant Gene Resources of Canada, Saskatoon Research Centre, Agriculture and Agri-Food Canada, Saskatoon, Canada, 2011 (unpublished work).

46. Hamrick, J.L.; Godt, M.J.W. Allozyme diversity in plant species. In Plant Population Genetics, Breeding and Gentic Resources; Brown, A.H.D., Clegg M.T., Kahler A.L., Weir B.S., Eds.; Sinauer Associates: Sunderland, MA, USA, 1989; pp. 43-63.

47. Moncada, K.M.; Ehlke, N.J.; Muehlbauer, G.J.; Sheaffer, C.C.; Wyse, D.L.; DeHaan, L.R. Genetic variation in three native plant species across the State of Minnesota. Crop Sci. 2007, 47, 2379-2389.

48. Qiu, J.; Fu, Y.B.; Bai, Y.; Wilmshurst, J.F. Genetic variation of remnant plains rough fescue (Festuca hallii) populations was weakly differentiated but geographically associated across the Canadian prairie. Plant Species Biol. 2009, 24, 156-168.

49. Weir, B.S.; Cardon, L.R.; Anderson, A.D.; Nielsen, D.M.; Hill, W.G. Measures of human population structure show heterogeneity among genomic regions. Genome Res. 2005, 15, 1468-1476.

50. Volis, S.; Olsvig-Whittaker, L.; Anikster, Y. The influence of space in genetic-environmental relationships when environmental heterogeneity and seed dispersal occurs at similar scale. Am. Nat. 2004, 163, 312-327.

(C) 2011 by the authors; licensee MDPI, Basel, Switzerland. This article is an open access article distributed under the terms and conditions of the Creative Commons Attribution license (http://creativecommons.org/licenses/by/3.0/). 